University of Nebraska - Lincoln

DigitalCommons@University of Nebraska - Lincoln

Faculty Publications, Department of Child, Youth, and Family Studies

Child, Youth, and Family Studies, Department of

2020

The meanings and ways of parental involvement among lowincome Filipinos

Aileen Garcia

Maria Rosario de Guzman

Follow this and additional works at: https://digitalcommons.unl.edu/famconfacpub

Part of the Developmental Psychology Commons, Family, Life Course, and Society Commons, Other Psychology Commons, and the Other Sociology Commons

This Article is brought to you for free and open access by the Child, Youth, and Family Studies, Department of at DigitalCommons@University of Nebraska - Lincoln. It has been accepted for inclusion in Faculty Publications, Department of Child, Youth, and Family Studies by an authorized administrator of DigitalCommons@University of Nebraska - Lincoln. 


\title{
The meanings and ways of parental involvement among low-income Filipinos
}

\author{
Aileen S. Garcia' and Maria Rosario T. de Guzman² \\ 1 Department of Counseling and Human Development, South Dakota State \\ University, United States \\ 2 Department of Child, Youth and Family Studies, University of Nebraska- \\ Lincoln, United States \\ Corresponding author - A.S. Garcia, Department of Counseling and Human Develop- \\ ment, South Dakota State University, 1175 Medary Ave., Brookings, SD 57006, United \\ States. Email aileen.garcia@sdstate.edu
}

\begin{abstract}
Parental involvement in children's education is an integral component of young children's academic achievement. Although there is clear evidence regarding the benefits of parental involvement, little is known regarding its impacts, manifestations, and conceptualizations in non-Western societies. Given that parenting and child rearing are imbued with cultural meaning in many profound ways (Super \& Harkness,1986), this study employed a phenomenological approach and used pakikipagkwentuhan, a data collection procedure drawn from indigenous Filipino Psychology to closely examine how low-income Filipino parents conceptualize parental involvement and its role in their children's education. Thirty-one parents/caregivers were engaged in conversation and qualitative data analysis showed that Filipino parents believe that helping their children with schoolwork, motivating them, and providing structure
\end{abstract}

Published in Early Childhood Research Quarterly 53 (2020), pp 343-354

doi: https://doi.org/10.1016/j.ecresq.2020.05.013

Published by Elsevier Inc. Used by permission.

Submitted 11 December 2018; revised 19 May 2020; accepted 26 May 2020. 
at home help their children succeed in school, consistent with the extant literature. However, responses regarding academic socialization, communicating with teachers, and volunteering in school reflect cultural beliefs and practices in the Philippines related to traditional parenting and extreme poverty. Results from this study expand our current understanding of parental involvement and highlight the role of the ecocultural context on parenting. Findings have implications for how parents and educators can support the academic success of children in culturally grounded ways. This study can also help inform educators and school programmers on how to help low-income parents support their children's education.

Keywords: Parental involvement, Filipino, Parenting, Elementary school, Low-income families

\section{Introduction}

Parental involvement $(\mathrm{Pl})$ is vital to young children's motivation and academic achievement (Fleharty \& Edwards, 2013). PI is linked to children's academic outcomes such as levels of school readiness(Miech, Essex, \& Hill Goldsmith, 2001), reading proficiency, math, and vocabulary skills (El Nokali, El Bachman, \& Votruba-Drzal,2011). With parental involvement comes information on what and how best to teach or support children (Pomerantz, Moorman, \&Litwack, 2007) and conveys the message that parents are interested and invested in their children's development (Hango, 2007). Consequently, children are more likely to internalize values that parents place on education and may gain more positive views about their own learning (Marcon, 1999) (for a review, see Pomerantz et al.,2007).

Nonetheless, little is known regarding the impacts, manifestations, and conceptualizations of PI non-Western societies - an important gap given that parenting and childrearing are imbued with cultural meaning in many profound ways (Super \& Harkness, 1986). In this study, we examine how low-income Filipino parents conceptualize parental involvement and its role in children's education. By focusing on an understudied population and on parents' points-of-view, we intend to expand current understanding of parental involvement and to shed light on potentially unique conceptualizations of PI. By exploring how PI operates in a cultural and economic context outside of the more represented populations in this field of study, we may expand our theoretical understanding of the construct. 


\subsection{Parental involvement as a construct}

Parental involvement generally refers to the parent's interaction with the child and the school to promote educational success(Edwards \& Kutaka, 2015; Hill et al., 2004). Pl is a multidimensional construct that includes cognitive, affective, and behavioral facets of parenting which are related to children's education (Clarke, 2001; García Coll et al., 2002). Scholars have also acknowledged that parental involvement comes in many forms. Epstein (1995)proposed a typology that consists of six dimensions of the con-struct, namely parenting (providing parents with resources and skills to help them foster child development at home), home-school communication, home learning activities, volunteering at school, decision-making, and collaborating with the community.

Within Epstein's typology, parental involvement is also commonly divided into three categorizations: home-based involvement (e.g., monitoring schoolwork, providing other enriching activities), school-based involvement (e.g., parent-teacher communication, attending and/or volunteering at school events), and academic socialization (e.g., communicating expectations and pro-viding encouragement to the child) (Eccles \& Harold, 1993; Seginer,2006; Wang \& Sheikh-Khalil, 2014). These typologies are reflected in commonly used measures such as the Family Involvement Questionnaire or FIQ (Fantuzzo, Tighe, \& Childs, 2000), which assesses school-based, home-based, and home-school conferencing. Another measure is the Parental Involvement Scale, adapted by Georgiou (1996), that referred to education and learning-related activities in which parents participate at home and school.

Despite the substantial scholarship defining and describing PI, nonetheless, much of the current research has been conducted with middle-income, Western populations. As such, current definitions and conceptualizations are generally premised on a very limited population. Additionally, scholars note that the predominant view of parental involvement is institution-driven in that the school mainly dictates what constitutes parental involvement(Clifford \& Göncü, 2019; Clifford \& Humphries, 2018; McWayne,Melzi, Schick, Kennedy, \& Mundt, 2013). It is unclear if parents, especially those who do not belong to the dominant population in research, may hold unique conceptualizations of, and practices related to involvement that may not be captured by the mainstream conceptualizations. 


\subsection{Parental involvement and the ecocultural context}

There is scholarly consensus that the context in which a child grows up has important implications for his development and that understanding almost any aspect of parenting must acknowledge the role of cultural values, beliefs, and norms (Bronfenbrenner \&Morris, 2006; Super \& Harkness, 1986). For example, the seminal work of John and Beatrice Whiting emphasized both the broad cultural context and the primacy of the immediate learning environment (e.g., physical space, activities, norms) in shaping children's outcomes (Edwards \& Bloch, 2010; Weisner, 2010). Elements of the Whitings' psychocultural model (Whiting, 1994) are reflected in the works of many of their students who similarly tried to 'unpack' the complex nature of 'culture' as reflected in the everyday experiences of children (Edwards \& Bloch, 2010 for review), such as Super and Harkness' (1986) developmental niche model, Rogoff's(Rogoff et al., 2007) concept of children's learning through intent participation in a cultural community, and Weisner's (1997) ecocultural theory that places prime importance on the developing child's family, everyday activities and routines, which are also embedded in a broader social and cultural ecology. Additionally, Göncü and colleagues highlighted the key roles of the economic context, the society's value system, and the intersubjectivity between care-

giver and child in understanding children's behavior (Göncü, Tuermer, Jain, \& Johnson, 1999).

These various theories together suggest that a child develops in both a symbolic and concrete context and that elements of their everyday experiences reflect the broader social and ecological context. Cultural context may affect parental involvement via parental cognitions, which include goals and expectations for the child, beliefs about childrearing and education, and perception of what the child needs (Harkness \& Super, 2006). For example, although there is considerable variation within culture groups, literature shows that in independence-oriented societies, children's socialization and the bulk of primary care are expected to be carried out by parents rather than distributed to multiple caregivers(Trumbull, Rohstein-Fisch, \& Hernandez, 2003). Thus, parents tend to take more responsibility themselves for their children's education, whether at home or in school (Baeck, 2010). Conversely, in some interdependence-oriented societies, parents are viewed as having the primary role of raising their children, 
whereas teachers are seen as experts and educational authorities who are not to be questioned (Denessen, Driessen, Smit, \& Sleegers, 2001; Hallinger\& Kantamara, 2001; Sy, 2006). This latter scenario leads to a some-what hierarchical relationship between parents and teachers with regard to education, and implications for parental involvement is yet to be explored.

\subsection{Parental involvement in the context of poverty}

Previous research has documented the impact of poverty on PI. For example, household income is an important predictor of $\mathrm{Pl}$, with children from high-income families receiving greater parental sup-port (Hornby \& Lafaele, 2011; Turney \& Kao, 2009; Usher, Kober, Jennings, \& Rentner, 2012; Yoder \& Lopez, 2013). Lee and Bowen(2006) maintained that low-income parents might not possess adequate social and cultural capital to feel comfortable connecting with the school. Similarly, Lareau (1987) asserts that social class shapes the nature of family-school relationships, with parents from low-income backgrounds being more likely to trust teachers' judgments as professionals, resulting in lower levels of parental involvement as traditionally conceptualized in the literature.

However, in Clifford and Humphries' (2018) review of studies among low-income and ethnic minority populations in the U.S., they found that parents may not be able to participate in their children's schooling in a more traditional sense (e.g., communicating with teachers), but instead are more likely to engage in home- and communitybased activities that support children's learning (e.g., involving children in their work). Clifford and Humphries (2018)thus advocate for an expanded view of parental involvement that is conceptualized by both the home and school environments, where families' cultural values and life contexts are considered.

\subsection{The Filipino family and education}

Although there is substantial variation in the nature of Filipino families, research suggests that the traditional Filipino family tends to be characterized by strong cohesion among immediate and extended family members. Obedience, respect for elders, fear of God, and meeting familial obligations are highly valued and are taught to children 
at an early age. Filipino terms such as hiya(shame) and utang na loob (debt of gratitude) are also pivotal values in the Filipino culture (Alampay, 2014). In all, Filipino parents are described to be nurturing and supportive (De la Cruz, Protacio, Balanon, Yacat, \& Francisco, 2001), and one of the Filipino family's primary and important functions is to educate the children (Reyes\& Resurrection, 2015). Filipino parents view education not only as an investment for their children, but also for the whole family(Blair, 2014; Medina, 2001; Ying \& Han, 2008). Correspondingly, a study among Filipino college students showed that they value education as a way of fulfilling familial obligations (Reyes \& Galang,2009). Reyes and Galang (2009) also maintained that the family contributes positively to students' motivation in school.

Empirical studies on parental involvement in the Philippines is limited, particularly among the low-income population. Nonetheless, Blair (2014) found that middle- and high-income Filipino parents reported high levels of involvement with children's homework and in volunteering for school related tasks. In another study, Filipino parents reported frequently reminding their children of the importance of going to school (Tabbada-Rungduin, Abulon, Fetalvero, \& Suatengco, 2014). Many parents in the same study also reported that they believed that they are their children's first teacher, especially in learning how to read. Given that children from disadvantaged backgrounds in the Philippines do not get enough support (e.g., insufficient school materials, shortages of classrooms and teachers, lack of financial assistance, (Philippine Institute for Development Studies, 2012) and many parents are not equipped with skills to support their children's education, it is essential to investigate this topic and explore how Filipino parents help and contribute to their children's academic success.

\subsection{Education and poverty in the Philippines}

The Philippines is a developing country with high rates of poverty and education deficits. School dropout rates are also high especially among children and youth from disadvantaged back-grounds (Albert, Dumagan, \& Martinez, 2015). According to the2010 Annual Poverty Indicators Survey conducted by the National Statistics Office in the Philippines, lack of personal interest in school and the high cost of education are the top two reasons why Filipino youth do not attend school. To help augment this problem, the Department of Social 
Work and Development leads a program called Pantawid Pamilyang Pilipino Program (4Ps). This program, piloted in 2008, provides conditional cash grants to poor families in order to improve educational and health outcomes, among others. To receive the subsidy, though, children need to be enrolled in school and must show consistent class attendance. This must have motivated parents to keep their children in school as high compliance rates were noted in 2015. Nonetheless, despite government efforts to improve the access and state of education in the country, such as participating in United Nations' Millennium Development Goal and allocating the biggest portion of the national budget for the Department of Education (Albert, Quimba, Ramos, \& Almeda, 2012), 36 million of the 6 to 24-year-old population is out-ofschool. That is one in every ten Filipino children and youth(Philippine Statistics Authority, 2015).

Although the public-school system in the Philippines offers free tuition until high school, many public schools have shown poor outcomes in national and international assessments compared to private schools. For example, in the National Achievement Tests where 75\% is the passing mark, fourth grade students from public schools had a mean score of only 68\% in school year 2009 -2010 (Yap, 2011). Thus, families who are more financially capable choose to send their children to private schools which tend to have better student-teacher ratio and quality of instruction. Filipinos, as a society, understand the value and importance of education, particularly as a poverty-alleviating tool for low-income families (e.g., securing employment is easier for those with a degree (Maligalig, Caoili-Rodriguez, Martinez, \& Cuevas, 2010)). However, experience of extreme poverty limits families' choices in terms of sending their children to school. Many lowincome families enroll their children in public schools, despite its academic reputation, for the subsidized education.

\subsection{The current study}

As noted in the literature reviewed here, current conceptualizations of parental involvement tend to reflect strategies that directly and immediately support children in school contexts (e.g., helping with homework) and in many ways reflect access to resources (e.g., volunteering for fieldtrips) and social/cultural capital (e.g., speaking with teachers/administrators, advocating for the child). What may be 
missed by the current literature, therefore, is how parents in lower resource contexts conceptualize involvement that capitalize on the resources that they have; as well as how parents inn on-Western contexts might utilize culturally-accepted ways of involvement that reflect interdependence-oriented strategies and the hierarchical views around schooling. The goal of this study is to explore whether those types of conceptualizations are reflected in low-income Filipino parents' notions of PI.

It is difficult to speculate on low-income Filipino parents' conceptualizations of parental involvement given the paucity of related research on the matter. Nonetheless, drawing from the literature reviewed here, one might expect that parents will express deep valuation of children's education, given how children's schooling is seen in Filipino contexts as reflecting the broader family, and how low-income parents in the Philippines tend to see schooling as a potential way to escape poverty. One might also expect parents 'conceptions to reflect a hierarchical view of academic expertise typically found in Asian collectivist societies (e.g., Hallinger \&Kantamara, 2001), such that teachers and school personnel are the experts who can dictate matters around children's education, as well as parents' roles in the process. This hierarchical conception would also be consistent with scholars' assertions regarding how low-income parents may have less social capital to direct their children's education and as such might still be actively involved in children's schooling, but in less direct ways and/or as dictated by those they see in authority.

\section{Methods}

\subsection{Participants}

Participants for this study were low-income parents of third-grade students. Third-grade was selected as this is the time when academic demands start to increase, and students are still too young to meet school requirements independently. As such, this grade level presents an opportunity for parents to be actively involved in their children's schooling. There was no age, educational attainment, or gender preference for the participants, as long as they have at least one child in third grade enrolled in the public school. The final sample consisted 
Table 1 Demographic characteristics of the participants and their children.

\begin{tabular}{lrrr} 
& $\begin{array}{r}\text { Mean (SD) or } \\
\text { Frequency (\%) } \\
\text { Variable }\end{array}$ & & \\
\hline Age & $(N=31)$ & Min & Max \\
Years of education & $36.65(8.11)$ & 27 & 63 \\
Target child's age & $10.10(2.02)$ & 6 & 14 \\
Number of children & $8.64(.84)$ & 1 & 8 \\
Target child gender (male) & $2.87(1.82)$ & & \\
Employed Part-time & & & \\
Full-time & $8(25.8 \%)$ & & \\
$\quad$ Not employed & $3(9.7 \%)$ & & \\
Monthly household income (USD) & $20(64.5 \%)$ & & \\
80 or less & $5(16.1 \%)$ & & \\
81-160 & $5(16.1 \%)$ & & \\
160-250 & $11(35.5 \%)$ & & \\
$251-410$ & $3(9.7 \%)$ & & \\
411-600 & $3(9.7 \%)$ & \\
Undisclosed & $4(12.9 \%)$ & \\
\hline
\end{tabular}

of 27 biological mothers, one biological father, one grandmother, one adoptive mother, and one legal guardian/aunt. Majority of the participants were not employed, and this is typical of the traditional caregiver role of the mother, as well as the high unemployment rates in the Philippines. Following research indicating that parent involvement is linked to academic outcomes, the participants were grouped according to their children's academic performance. Ten of them were from the high-achieving group, 11 from the average group, and 11 were from the underachieving group. Table 1 shows a summary of the participants' and their children's key demographic characteristics.

\subsection{Research site}

This study was conducted in a community in Caloocan, a city in Metro Manila with a population of 1.58 million, making it the third most populous highly urbanized city in the Philippines (Philippine Statistics Authority, 2016). Caloocan has a very high population density (28,387 persons/sqm) as well as high rates of poverty. The city is 
a part of the third district of Metro Manila, which has a poverty incidence rate of 2.7 to $5.5 \%$ (i.e., $\$ 181$ USD/year, the minimum amount required to support the needs of a 5-memberhousehold) (Philippine Statistics Authority, 2016).

One public school in Caloocan was chosen as the research site. A previous partnership with this public school enabled the researchers to more easily communicate with the principal and the teachers who helped with recruitment. The characteristics of this school and its students also make it a good site to study parental involvement. For example, it has a student population of 5125 in academic year 20132014 and has 54 instructional classrooms, making its student-teacher ratio high. Although most public school students come from underprivileged communities, this school particularly caters to very low-income families who have difficulty meeting basic needs. Although the first author's personal communication with the school's teachers revealed that many students drop out before graduating from elementary school, the teachers also mentioned that they do not maintain a record of the school's success rates. The Philippine education system uses English as its primary medium of instruction. However, Filipino or Tagalog remains to be the first language of most children and the language used in everyday conversation. For those who are able, English is mostly spoken in more formal settings.

In terms of expectations regarding parental involvement, participants reported that to their knowledge, the school does not provide a handbook that outlines the school policies, grading system, and expectations from students and parents. Although the parents reported that the teachers encourage them to be involved in their children's schooling (e.g., tell the parents to teach the children at home), the school does not have an official program or a systematic approach on teaching specific strategies on how parents can support their children.

\subsection{Recruitment and data collection procedures}

The researchers employed purposive sampling with the help of the school (i.e., the school principal and one classroom adviser, equivalent to homeroom teacher in the U.S.) to identify potential participants in terms of students' academic grades. To ensure representation, we invited parents of high-achieving, average, and underachieving students according following the classroom adviser's criteria. High-achieving 
group was composed of students who are in the "star" or first section; underachieving group was composed of students who were on probation or were required to attend remedial classes; and average students were those in between. Upon identification of the potential participants, recruitment letters were sent to parents through the school with the instruction to contact the school or the researcher if the parent is willing to be interviewed. The first author then contacted the interested parents through phone call and/or text message to provide a brief overview of the study and what the participation entails. A date and time for the interview were set for parents who agreed to participate. The participants were also given the choice on whereto have the interview, but all of them chose to be interviewed in the first author's home. This was most likely for convenience as the home was close to the school. Additionally, the parents may not have been prepared to receive the first author as a guest in their respective residences. Recruitment continued until data saturation was reached, when it was apparent that information has become redundant and no new information was forthcoming.

An informed consent, detailing the objectives of the study, potential risks and benefits, and contact information of the researchers, was read to the participant prior to the start of the interview. Each interview lasted from 19 min to 71 min, averaging39.13 min in length. Interviews were conducted mainly in Filipino language, with frequent insertions of English terms, as is typical in casual conversation in the Philippines. Following previous parenting research projects in the Philippines, PhP 300 (approximately USD 6.00) was given to each parent for their time and participation.

In addition to conducting the interviews, the first author diligently kept a record of her observations during the interviews and reflections throughout data collection. Bernard (2006) identified three types of field notes and these three were utilized in this study. First, there were methodological notes where thoughts and insights on recruitment and data collection procedures were logged. Second, descriptive notes included reflections on each interview were recorded, as well as the researcher's personal reactions and perceptions of the interview. For example, one mother emotionally recounted the child abuse she experienced from her stepfather, and that provided a context as to why strives to provide the best for her daughter. Both interviewer and participant spent a significant amount of time processing this emotional 
experience. Finally, analytic notes contained initial reflections on the participants 'responses and ideas on emergent themes. Because of the informal nature of the interview, some participants continued speaking and sharing their experiences even after the interview has ended. The field notes were helpful in providing these details that were no longer audio recorded.

\subsubsection{Sikolohiyang Pilipino}

The data collection procedure for this study drew from the research methodology of Sikolohiyang Pilipino (SP), which is the psychology that is born out of the experience and orientation of the Filipinos (Enriquez, 1994). In SP, it is important to examine and understand the local language and to explain the phenomenon through the lens of the native Filipino in order to develop knowledge that is contextualized within indigenous concepts (Pe-Pua \&Protacio-Marcelino, 2000). SP's approach is regarded as "indigenization from within" where conclusions are directly derived from the experiences and socio-cultural realities of the Filipino people(Pe-Pua \& Protacio-Marcelino, 2000).

This study utilized the indigenous method of pakikipagkwen-tuhan (exchanging stories). This can be likened to the traditional method of interviewing, except for the role of the researcher and the participant and the manner of data collection. Pakikipagk-wentuhan has three main characteristics: emphasizes equal status between researcher and participant, participatory in nature, and sensitive to Philippine norms and contexts (Pe-Pua, 2006). For example, during the interviews, the first author asked the participants to not call her "Ma'am" as is typical in formal conversations. The participants also asked the first author questions and some-times volunteered information outside the scope of the interview.

Further, in pakikipagkwentuhan, the researcher motivates the participants to narrate their experiences about the topic. Pakikipagkwentuhan aims for systematic procedures, for example, using a semistructured predetermined interview protocol. However, flexibility was allowed in the questions (e.g., adding or omitting questions when deemed appropriate) and each interview was set in a less formal tone that can be more likened to a friendly, casual conversation. In addition, prior to starting the interview, the first author tried to build rapport with the participant by engaging her in conversation and by sharing a 
light snack at her home. Rapport-building is very important, especially in $S P$, to minimize the gap between researcher and participant and to help facilitate a comfortable relationship between the two (pakikipagpalagayang-loob; Pe-Pua \& Protacio-Marcelino, 2000). This approach was used as this has been found to be culturally-sensitive and more appropriate in doing research with Filipino samples (de Guzman, 2014).As a result, before, during, and after the interview, the first author and the participants freely asked questions not related to parental involvement. For example, during one interview, a few minutes were spent talking about a favorite Filipino snack, and the mother offered to give some later that day. Another one inquired about the first author's life in the US.

\subsection{Instrument/protocol}

As parental involvement is a multifaceted construct that includes cognition, affect, and behavior, the interview protocol included questions on educational beliefs, academic expectations, and parental practices at home and in school. Parental involvement is also influenced by cultural factors that reveal distinct parental values and goals (Malone, 2014; Usher et al., 2012). These values and goals provide a context for the involvement strategies parents employ. Thus, Filipino cultural concepts related to parenting, beliefs on child development, and value of education were also asked. Sample questions included "How important is education for you?", "What are the things you do at home to help your child with his/her schooling?" and "What does your child's school do or offer to involve you in your children's education?"

\subsection{Data analysis}

Data analysis was guided by interpretive phenomenology. This approach acknowledges that the researchers cannot entirely remove themselves from the meanings obtained from the inter-views. Moreover, the researchers' subjective views and beliefs help in interpreting and, subsequently, understanding them. Interpretive phenomenology was used in this study as its tenets are more suitable to the present study's research goals. In this study, exploring the meaning and the nature of parental involvement and how it relates to children's academic outcomes relied not only on the narratives of the participants, 
but also on the researcher's knowledge of the construct and interpretation and examination of the interviews and field notes.

The interviews were audio-recorded and transcribed verbatim by a professional transcriptionist fluent in both Filipino and English as the interviews included both Filipino and English terms. The interviews were coded in the original language to ensure that the meanings of responses are preserved, following the steps in doing phenomenological study (Castro, 2003; Creswell, 2007). First, the transcriptions from all three groups were read several times by achievement group as the first author searched for patterns and emerging insights from the participants' experiences (holistic approach). This included highlighting significant statements that reflect the participants' experiences (Creswell, 2007) and to see the language the participants use to describe the phenomenon. For the second step, these highlighted statements, or meaning units, were then organized according to the interview questions.

The next step was to synthesize findings from the three achievement groups and incorporate insights onto the meaning units. Meaning units were then transformed into category labels to allow for a more systematic comparison of results with existing literature (e.g., "attending meetings" were coded under "communicating with teachers"). There are two levels to this step - situated structure and general structure (Castro, 2003). The situated structure refers to the concrete responses related to parental involvement, such as what parents do to involve themselves in or support their children's education. Afterwards, from these specific, situated structures, the researchers created a general structure or essential meaning of the phenomenon across the participants' responses. For example, responses related to what parents do at home were now described or categorized as homebased involvement.

As a last step, a general description of the phenomenon was formed, results of all steps in data analyses were integrated to develop a coherent understanding of the phenomenon. The researchers reviewed the codes to ensure that they were representative of the themes. Throughout this process, two other researchers who are both fluent in Filipino language and are skilled in qualitative research, served as external auditors to examine the codes and themes. 


\subsection{Validity and verification procedures}

To ensure validity of findings, three verification procedures from the strategies suggested by Creswell and Miller (2000) were conducted. First, we used rich and thick description of the participants 'experiences to give a vivid and clear narrative to the readers, giving them enough evidence to make sense of the study and to make decisions regarding transferability. Second, the results were presented to a group of about 20 researchers at a professional conference on cross-cultural studies. This audience was composed of non-Filipino graduate students and faculty members who provided feedback and additional insights on the findings. For example, a few audience members affirmed that the nature of volunteerism reported by the participants is very different from how parents in the U.S. volunteer in their children's school. They also asked further questions about the traditions and common practices among Filipino families to contextualize the participants' reported strategies in helping their children. This led to the addition of further descriptions of some concepts and behaviors to ensure that readers understand the context and the interpretation of findings.

Lastly, the researchers continuously engaged in reflexivity. In phenomenological research, it is very important that the researcher's subjective views and potential biases are made explicit(Creswell, 2007). As Filipinos, both researchers share a similar cultural background with the participants. For the first author, in particular, this served as a common ground to give way to a smooth interaction with the participants. Although the first author attended a private school in elementary school, she did go to a public high school in the Philippines and has experienced first-hand the challenges of having inadequate school facilities. In addition, she had regular interaction with families in poverty through her participation in research projects on poverty and through community outreach endeavors.

On the other hand, the researchers also acknowledged the potential biases and differences they may have with the participants. They have a different socioeconomic background from the participants and their definition and experience of poverty may have been different from the participants' experiences. As such, every attempt was made to remain objective and grounded on the data. The researchers 
constantly referred to the recorded fieldnotes to aid in data analysis. Having two external auditors who are also fluent in the language and know the Filipino culture helped ensure that the researchers' personal biases did not undermine or overpower the experiences of the participants.

\section{Results}

Themes and subthemes are outlined below, together with supporting quotes to provide rich description of participants' experiences. Participants are identified with pseudonyms. Meaningful differences across the three achievement groups in terms of how they exhibit parental involvement did not emerge. As such, we present the findings below without regard for the participant groups. Participants were asked about their views on education and their role in helping their children succeed academically. Responses to these questions provide the meaning of parental involvement for the participants and the specific strategies they employ to sup-port their children's education. All participants stated that going to school is important and that education is perceived as a tool to escape poverty. Trina, 40, mother of 3 , noted, "For me, education is very important. If they (children) don't get to study, they won't have a bright future. They won't get a good job." This is similar to Myla's, mother of 5, statement, "It's (education) the only treasure we can leave behind. Even if we don't have land or anything, as long as they graduate, they can get a good job." Holly, 34 , mother of 2, further asserted the importance of education despite having financial difficulties. She said,

"For me, it's unavoidable not to have money problems ... But if you think about it, you can do both -work and send your child to school. If you don't have a job, work as a laundry woman. What's important is that you send the child to school ..."

Participants' descriptions of their support and involvement generally fell into four main themes: (1) home-based involvement, (2)schoolbased involvement, (3) academic socialization, and (4) pro-viding for the child's needs. Subthemes for each larger theme are also discussed. 


\subsection{Theme 1. Home-based involvement}

Home-based involvement includes activities such as monitoring the child, assisting with homework, and providing other enrichment activities for the child to learn (Eccles \& Harold, 1993).Participants reported that as parents, one of their roles is to help their children in their schoolwork; thus, they engage in home-based involvement. Across all three groups, responses reflected beliefs on home-school partnership where parents perceived themselves as having an active role in helping their children learn and that they can do something at home to facilitate their children's learning. as Wilma, 39, said, "Teachers and parents need to help each other for the benefit of the child. It's not right that the teachers will do all the work. Parents should also teach the children at home. Before they go to school, teach them. So that when they go to school, they'd know how to respond to the teacher's questions." The home-based involvement theme is divided into two subthemes: monitoring the children regarding school work and engaging in different learning activities at home.

Monitoring the child. Monitoring involves asking the child about what happened in school, if there were homework, and checking up on the child's activities. Thirty (96\%) participants mentioned that closely monitoring their children keeps them updated on what they should teach their children. One. For example, Holly mentioned in the interview that she focuses on her son's studies. She detailed, "When he gets home from school, I'd ask him what they did, if they have an assignment, if they had a test. Things like that. For me, as soon as he gets to the gate of our house, l'd ask, 'What did you do? Did you read?' I'd ask him right away." Sonia,29, said, "I always check on my daughter, I look at the things she needs for school. And I also teach her. You should have time for her to help her review."

Several participants also said that even though their children can do the homework on their own, they still checked on them to see if their answers were correct. Monica, 29, described her daughter, "She would do her homework and then I would check it, and that's when I would tell her what's missing ... " Similarly, Vivian,31, mentioned, "When they have homework and they know how to do it, they will do it on their own. But I tell them that if they don't know the answers, they should ask me. Even if I'm doing laundry, I'd ask them if they have homework and I would respond if they have questions." 
Engaging in home learning activities. A second way by which parents described home-based involvement is in engaging in activities that introduce or reinforce school lessons, such as purposely allotting time to teach the child. Twenty-nine (94\%) participants described helping their children with homework and projects. For example, Fiona, 40, who works part-time, said, "I tutor my son on his assignments no matter how busy I am." Carol and Erica both responded that they teach their children at night, as a follow-up to what they learned in school earlier that day. Erica added, "Every night I'd teach my daughter how to read. Before we sleep, we would read first ... Any English book." Karen, whose son was having academic problems, shared, "I have to help him because if I don't, then nothing, he will just be like that."

Parents also reported practicing more intense teaching when their children have upcoming exams. As exams carry a big percent-age of the grades, parents reported studying with their children more thoroughly and constructing reviewers that their children can answer. Kris said she would review with her son by asking him questions that she has constructed from the school lessons. Christy mentioned she would write a summary of each day's lessons that her daughter can review. Aurora and Aida both mentioned that they create practice exams for the children to answer.

Only three (10\%) respondents noted teaching their children ahead of the lessons they are currently teaching in school. These parents also acknowledged that studying at home should not be limited to simply completing the child's assignments. For example, for Aida, 63, who is the primary caregiver of her only granddaughter as her daughter (mother of the child) works overseas, she makes sure to teach the child and noted, "I do teach her lessons in advance because the textbooks are there anyway." Teaching advanced lessons was also something Monica used to do with her daughter. However, she thought that it might be the cause of the problem why her daughter now is having a hard time in school. When asked if she teaches her daughter in advance, she responded, "That was perhaps the problem with me ... Because I wanted her to learn things right away even if her brain could not handle it yet." 


\subsection{Theme 2. School-based involvement}

Participants believe that parents and teachers should work together in order to optimize children's learnings. As such, most participants reported actively participating in school-led activities and reaching out to the teachers when necessary. More specifically, responses under school-based involvement fall under communicating with teachers and volunteering in school.

Communicating with teachers. The participants deemed an open home-school communication is necessary if they would like their children to succeed. In this particular school, parents are required to come to school to claim their children's report card at the end of each quarter. All 31 (100\%) participants said that they come to school for this, and some of them noted that they take this opportunity to ask the teacher about their children. Carmela said, "I always attend because I want to be in-the-know. I wouldn't want to be late in learning about news, that there's something happening, and we didn't know about it."

Aside from these quarterly meetings, the teachers would also call on some parents if the students were having problems. Linkedln Karen's case, her son has been having academic problems and he might repeat third grade if he does not attend summer school(remedial lessons). She shared, "The teacher would tell my son that she needs to talk to me. When that happens, I get scared. Because I already know what she's going to say, that I need to guide him and follow up at home. That's what the teacher always says ... I get shy because the teacher said he reads slowly, and that he's not able to finish some seatwork." Ivy's son was also supposed to repeat second grade but she was able to request the school not to let it happen(napakiusapan). Although Ivy said that she attends the meetings, she admitted that she dreads going to those:

The teacher would say, "Mommy, your son is like this, he doesn't do much, he doesn't write." And I would say that my son some-times can't understand instructions in English, and that he gets confused in English and Tagalog. I'd prefer Tagalog. My son knows how to understand, it's just that English is the problem. I told the teacher that my son said he 
speaks so fast, and the teacher apologized and said that the lessons are fast-paced. So that's why students who can't understand get left behind.

Aside from attending teacher-initiated meetings, participants also reported taking on a more active role by contacting their children's teachers, especially when there were concerns surrounding the children's behavior. For instance, Trina said that she would talk to the teacher only when necessary, just like when her daughter was mistakenly blamed to have been involved in a fight in the classroom. Erica also said that she talked to the teacher about her daughter's experience of getting bullied as this interfered with her concentration in school.

Some participants also reported initiating communication with the teachers for academic-related questions. Lyka recounted an instance when she asked the teacher why her son's grades dropped so suddenly, noting, "I don't think it's bad to ask questions, right? "For Monica whose daughter has been having a difficult time under-standing the lessons in school, it is important that she is regularly communicating with the teacher. She shared,

"Every other Friday I would go to school to ask about my daughter's problem, and they would tell me to talk to her ... The teacher would not ask me to come, I would just go and ask."

Volunteering. Twenty-seven (87\%) participants reported volunteering their time to help in the school. Majority of the participants help in cleaning the school before classes start, mainly because this is highly encouraged and is a country-wide program in the public schools - Brigada Eskwela or Brigada, for short. In this program, parents are invited and encouraged to help clean their children's wouldbe classroom and to help the classroom adviser. Veronica said that she always joins the Brigada, owing to her many children enrolled in the school. Yoli, Sonia, and Karen also shared that they help in the school's general cleaning. Eleven other participants mentioned that they join the Brigada.

Given the limited number of staff in the public school, teachers also ask for parents' assistance when they need additional manpower. 
Participants recounted helping in activities such as classroom parties, contests, and club meetings. Fiona said, "I'd help out during the class Christmas party, things like that. Even if I'm not an officer, they'd call on me ... I'm willing to help with anything. "Trina mentioned that she has previously helped in the school's feeding program (akin to the lunch program in the US). Christy's case is different as she is sometimes called to do personal errands for her daughter's teacher. She said,

"The teacher likes to call on me for different things, like if there's a student who needed help in the restroom, as there's no one else to help the child clean. That's one of the teachers' problems here. And then she would ask me to come to school and print some papers for her ... Or when she sees me in the morning inside the school when I bring my daughter, she would ask me to make her coffee."

More volunteer time was reported by participants who have taken on leadership roles in the Parent-Teacher Association (PTA).As officers, they are the primary person to rely on when teachers need help. For example, As the PTA president in her granddaughter's class, Aida added that they would be the first to respond when money is needed, when there are other things needed in the class-room such as floor wax, or when they need to cleanup because some school guests would be coming. Erica used to be an officer as well. However, she found herself paying for parents who were notable to give their monetary contribution, so she decided not to run for the position the succeeding year. She did note, however, that money problem aside, she really liked that role as she was able to help the teacher.

\subsection{Theme 3. Academic socialization}

Aside from home-based and school-based involvement, participants also engage in academic socialization practices. These practices are geared toward helping their children understand the value of education and develop good study habits (Wang \&Sheikh-Khalil, 2014). This theme includes the following: motivating the child, establishing rules and routine around studying, giving rewards for positive academic outcomes, and administering punishment for undesirable outcomes. 
Motivating the child. Thirteen (42\%) participants reported motivating their children by acknowledging their efforts and encouraging them to do their best. Yoli recalled the time when his son received high grades on his report card. When asked how she felt, she described:

Of course, I was very happy because we can see what we worked hard for, including me ... I told him, 'Son, I hope it's always like this, high grades. You can now go up the stage (for recognition)just like what you wanted ... "'"

Karen would also encourage her son by telling him, "Son, just continue with your studies. Even if we're poor, we can do this. Your Papa is there to help as well." Similarly, Ivy would tell her son who is struggling in school, "Son, just a little more perseverance... Do you want to move up to fourth grade or do you want to repeat third grade? You have to persevere (magpursigi) ..." Fiona, she would simply push and tell her son, "Son, you can do it!" As these sample quotes illustrate, participants see the importance of motivating the children and how it helps them do better in school. One participant even mentioned that motivating her children is the most she could do, especially when she is unable to help the children with the lessons. Myla said, "I can't contribute anything, especially when it comes to Math and English ... What do I know about that? That's why all I can do is push him. That's what I do."

\subsubsection{Establishing rules and routine around studying}

Twenty-seven (81\%) participants also mentioned that they have rules at home to help provide structure for their children and their studies, acknowledging that there should be a time for studying and time for playing. For Yoli, her son is only allowed to play basketball on Saturdays and Sundays. Aurora shared that her children know that they are not allowed to watch TV if they have an exam, similar to Holly who does not allow TV-watching on weekdays.

Some participants shared their routines at home which prioritize studying. For example, Emie shared, "When he gets home afterschool, we would eat, then I would tell him to read before we watch 
Probinsyano (a popular soap opera in the Philippines)." For Christy, she said, "As much as possible, when my children get home from school, as soon as they get home, I want them to open their note-books. Then after that, they can play. That's what I always say, there's a time for playing. And also summer is almost here, they can play then."

\subsubsection{Giving rewards for positive academic outcomes}

Twenty-eight (90\%) participants mentioned giving the children some form of reward when they do well in school. The rewards range from small monetary gifts to eating out at their favorite fast food. For example, Myla shared that she would promise her son 50pesos (1 USD) if he gets a perfect score on the test. But she added, "I actually don't give him the money; rather, he lists it down, and I would give him the money on payday. He takes note of it, and when it's his Papa's payday, he will collect it ..."

Twelve participants mentioned that they treat the children at Jollibee, a local fast food chain akin to McDonald's in the U.S., as a reward. Emie recounted that when her daughter needs to study, she would tell her, "Study hard, I will buy you this, we will eat out, we'll go to Jollibee." This is similar to Aida's case about her granddaughter who is at the top of her class, "My husband and I, we're always at Jollibee because when she gets a perfect exam score, we have an agreement ... We'll buy our dinner from Jollibee. Trina said that she also uses rewards for her daughter, especially when she wants something, but she makes sure that there are limits, "We don't do it all the time ... It's not like that, that we'd always give them something. Because what will happen if you don't have anything to give? ... You don't have to get them used to getting something each time they get high grades, right?"

In all, the responses show that parents give rewards to encourage their children and to reinforce positive behaviors toward studying. The promise of a reward also serves as an agreement between the parent and the child. Given the participants' limited budget, the promise of food and other basic necessities allows them to still incentivize their children's hard work. 


\subsubsection{Administering punishment for poor academic outcomes}

Twenty-nine (94\%) of the participants also mentioned trying to discipline and instill good study habits in their children by using a combination of punishment strategies such as giving reprimands and threats of, or actual, withdrawal of privileges. Several parents mentioned that they only use reprimanding or scolding as a way of correcting their children's poor study habits. When asked if hessians his daughter, Romeo said "No, I would just reprimand her(pinagsasabihan). I would just tell her to study what she missed in the test." As for Lyka, she shared, "I no longer spank, I'm just loquacious (mabunganga). I just use my mouth." Holly also shared what she tells her son who likes to draw, "Nothing will happen to you if you're only drawing. It (drawing) won't feed you ... It's not okay that you're just drawing all the time, nothing will happen to you."

Chloe and Holly both revealed that they give their children threats. Chloe recalled what she had told her daughter who had to take remedial classes, "... just tell me if you don't want to study anymore so that I won't ask you to go to school ... You'd see that I would peddle on the streets just to send you to school, and then you would just skip school? What will happen to you when you get older?" Holly said that it is sad that she has to scold her son. She would tell him, "If you don't do better, just don't study. Don't go to school tomorrow."

Aside from the disciplinary techniques mentioned above, four parents also reported using physical punishment, particularly spanking. They were careful to note, however, that spanking is coupled with a serious talk about the child's transgression. Emie shared that there were a few times when she would spank her child when she gets too fond of playing and forgets to open her books, "She would get spanked, but of course, mostly we just talk to her and give her advice." This is similar to Monica's experience with her daughter, "Sometimes I would spank her. But for me, if I span you, I would explain to you why I did it. I wouldn't spank you for no reason." Joyce also explained that she would spank her daughter, especially if she does not know her homework, but that she is conflicted when doing it:

My daughter would cry ... I also cry easily, so she would see me also crying ... Of course, as a mother, I don't want to see 
my child getting hurt by other people, even by my husband. I would really be crying when my husband spanks her, so I'd ask myself why I'd also do it ... Sometimes I would pity her when I scold her because she's really having a hard time, especially with Social Studies.

\subsection{Theme 4. Providing for the child's basic needs}

Many participants described responding to the children's needs as one way to ensure that their children are ready for school. Although this may seem as a fundamental parental obligation toward their children, the majority of the participants narrated stories depicting struggles in day-to-day living, given their high poverty context. Thus, even basic parental responsibilities are considered as specific means by which parents involve themselves in their children's education, like Aida who said that she supports her grandchild by "taking care of her, feeding her, and dressing her up every day." The rest of the responses for this theme are categorized below.

\subsubsection{Caring for the child}

Eleven (35\%) participants mentioned caring for their children as a way of parental involvement. Children's health was often dis-cussed by parents as their main priority. A number of participants specifically mentioned that they ensure that their children are well-fed and healthy so that they are fit to go to school. Christy expressed that it is the parent's responsibility to provide for the children's needs. She further shared, "I would prepare her food first, then ask her about her assignments ... Sometimes, while she's studying, I would just feed her. Otherwise, she would get hungry without noticing it." Myla mentioned prioritizing her son's health, "My son does not miss school ... as long as he's not sick. I even give him vita-mins so that he won't get sick." Trina also added that she shows her support for her children's education by "responding to the child's basic needs every day, helping them with their homework, and providing not only for food, but also the things they need in school." 


\subsubsection{Bringing the child to and from school}

Another basic need that parents respond to is ensuring that their children get to school safely and on time and 23 participants (74\%) mentioned this. Romeo and Carol stated that this is part of their daily routine. Yoli stated that she walks her son to school even though her son could actually walk by himself. She said, "He can do it by himself, it's just me who doesn't like him to walk by himself ... Because sometimes it's sunny, so it's hot while they're waiting inline so I need to hold an umbrella over her." Beth also shared,

"We don't let her walk by herself. Also, she's scared of dogs (stray dogs).She can't be by herself because when she sees a (stray) dog, she will run ... She got a phobia of dogs. And I also don't really want to leave her by herself even if she's already in third grade. As long as I'm able, I will bring her to school and pick her up (hatid sundo)."

\subsubsection{Other parental obligations}

Nine (29\%) respondents described several other parental obligations that comprised part of their support for children's schooling. This included their responsibility of working and earning money. Holly affirmed, "Of course, to persevere at work ... Because of course, if you don't have a job, where will you get money to spend for their schooling?" Watching over their children (bantayan) was also mentioned by Myla and Beth as a way of supporting their children. Carmela added that ensuring that her children have clean school uniform to wear every day is also one way of supporting them. Lyka stated that her and her husband's role should go beyond responding to the children's needs. She said:

Of course, we need to provide for what they need in school, but at the same time ... give them some opportunities to go out. So that they're not only concentrating on their studies all the time. Give them time for leisure and traveling (mamasyal), to get together with the family. Because that's really our bonding - for me and my husband, even if our income is not big, sometimes we would really allocate time for us to go out, eat out, play ... 


\section{Discussion}

Children grow up within contexts that reflect broader societal and cultural beliefs that are reflected in their everyday experiences, immediate settings, and the ways by which their caregivers provide nurturance and support. In this study, we explored how low-income parents in the Philippines conceptualize parental involvement in education a construct that has not been thoroughly explored outside of Western industrialized nations. Findings suggest complexity in parents' understanding of parental involvement in children's education - reflecting themes from the broader literature as well as beliefs that uniquely reflect the socioecological and economic spaces that participants occupy.

Scholars have identified several ways by which parents generally define and display involvement in their children's education and findings from this study reflect many of these categories (Eccles\& Harold, 1993; Epstein, 1995), such as helping with children's homework, volunteering in school, and establishing rules around studying. Despite overlaps between current findings and general parenting involvement typologies, parents' responses also revealed unique notions reflective of participants' socioeconomic context(Clifford \& Göncü, 2019; Göncü et al., 1999). For example, participants described responding to children's basic needs as a way of supporting their education. This specific finding draws attention not only to the parents' major role as a nurturer (Zellman, Perlman, \& Karam, 2014), but also hints at unique facets of participants' eco-nomic context. With insufficient, unstable income and unsecured employment, even responding to children's basic needs is a challenge for most of the participants. Further, as lowincome parents commonly tend have lower social capital compared to their children's teachers because of differences in social class (Lareau, 1987), this may limit their capacity to involve themselves in more direct ways (e.g., challenge authority of teachers, advocate for the child). Thus, parents may view their efforts to provide instrumental sup-port (e.g., by getting a job, taking a loan), although not exactly in congruence with teachers' and institutions' view of parental involvement, as intentional and direct ways to keep their children in school and support their education.

Some emergent categories of parental notions about involvement were also consistent with earlier research, but unique in their 
manifestation. For example, participants named volunteering in school as parental involvement, consistent with earlier research(Eccles \& Harold, 1993; Epstein, 1995). However, specific activities they noted included contributing to the upkeep of the child's school (e.g., cleaning), which is somewhat distinct and has not been reported in previous parental involvement studies across different countries. Because of very limited resources, public schools in the Philippines rely on the parents as allies to ensure that the school's physical environment is conducive to learning. Thus, activities that parents can assist with not only include activities typically seen in Western schools (e.g., volunteering for PTA), but also in the basic upkeep of the school such as cleaning the school. This also under-scores the interdependent nature of Filipinos, as well as the power distance between teachers and parents where parents oblige to teachers' or institutions' requests with little or no question.

Culturally embedded notions are also evident in respondents 'notions about involvement in children's academics, consistent with the ecocultural framework (Weisner, 2002). From the participants 'responses, it was apparent that the rules and routines set around studying and day-to-day living were informed by their belief in the importance of education. For instance, efforts to personally bring the child to and from school, as well as providing for the child's needs as a way of supporting children's education may be attributed to the Filipino cultural value of interdependence and the nurturing, and sometimes overprotective, nature of Filipino parenting (Dela Cruz et al., 2001). Participants also mentioned using inductive methods such as motivating and talking to the child, as well as disciplining strategies typically used in Philippine settings (e.g., physical punishment and giving reprimands, Lansford et al., 2010) in children's academic socialization. Although the use of strict discipline strategies is not unique to the Filipino culture, this has not typically been noted in the broader literature as a means of academic socialization. Moreover, although administering physical punishment and reprimanding may be considered punitive by Western standards, parents asserted that these are done out of concern for their children. This finding again reflects the nurturing aspect of Filipino parenting, as well as the high regard for obedience (Alampay,2014).

The interdependence and close-knit nature of the Filipino family is also evident in the importance parents place on their children's 
education. A common narrative among Filipino families in poverty is that education is the only inheritance they can leave with their children.

Filipinos also view education as an investment and a tool to alleviate poverty, not only for the individual, but for the whole family such that it is not uncommon to expect the older sibling to send the other sibling/s to school (Reyes \& Galang, 2009). These cultural priorities are evident in the participants' efforts to support their children's education in their own capacity despite their limited financial resources and social capital. Current findings show that Filipino parents are explicit in communicating the value of education to their children, and transgressions related to not taking school seriously are met with consequences.

In some ways, findings run contrast to some studies suggesting that given the distributed approach to care and socialization interdependence-oriented societies, parents may relegate responsibilities for academic socialization to formal educators (Denessenet al., 2001; Hallinger \& Kantamara, 2001; Sy, 2006). However, it is worth noting that there has not been enough nuance in this earlier body of work. Indeed, there is substantial variability in family situations and forms within what scholars have categorized as "interdependence-oriented" - rural versus urban, socioeconomic differences, parents' educational levels, geographic location, ethnic and racial differences, and others. Moreover, our research suggests that perhaps because involvement has been con-centralized and thus measured quite narrowly, in fact parents interdependence-oriented, low-income, and/or non-Western societies may conceptualize and express involvement in different ways. It was evident from our participants' responses that they strive to play an active, although possibly less salient and more indirect, role in their children's learning and education. To conclude, whereas some aspects of the meaning and nature of parental involvement among Filipino parents are consistent with mainstream literature(Eccles \& Harold, 1993; Epstein, 1995; Fan \& Chen, 2001), additional themes in this study underscore the variability of how parental involvement is conceptualized and expressed. Unique notions of parental involvement are a function of parents' socioeconomic and cultural backgrounds, revealing parenting behaviors that are not traditionally considered as involvement in education. 


\subsection{Strengths of the study}

For decades, scholars have argued for the need to situate the child and understand parenting in context; as well as the need to broaden the settings in which we study development (e.g., Edwards\& Bloch, 2010; Harkness \& Super, 2015; Weisner, 2002). The examination of many important constructs, such as prosocial behaviors(de Guzman, Brown, Carlo, \& Knight, 2012), moral development(Wainryb, 2006), and attachment (Keller, 2013), have benefited from expanding the range of samples and contexts to test the limits of current conceptualizations and to broaden the range of variables of interest (de Guzman, Carlo, \& Edwards, 2008). Although this study was not designed to develop findings that can be generalized broadly, studying parental involvement in a sample not typically represented in the current literature lends support to the ecocultural framework and yields important information about how notions and parenting practices related to children's education reflect both traditional conceptualizations, as well as unique beliefs and practices specifically reflective of their cultural and economic context.

Another strength of this study was contributing to the recommendation of Clifford and Humphries (2018) to involve the home environment in constructing the meaning of parental involvement. By incor-

porating the parents' perspective, results of this study more effectively captured the parents' efforts in supporting their children, expanding the predominantly institution-based conceptualization of parental involvement. Current findings also contribute to the diversity of the literature by capturing a cultural group that, by multiple standards, differ from the middle-class Western communities that usually inform theories in education and families (Clifford \& Göncü, 2019).

\subsection{Implications}

Several implications can be drawn from the current findings. First, themes culled from the data support earlier scholars' conceptualizations of parental involvement in education - suggesting generalizability in several of the categories identified earlier, such as home- and school-based involvement. Second, unique domains of involvement (e.g., providing for the child's basic needs) and unique instantiations of previously identified areas (e.g., cleaning the school as 'volunteering') 
suggest the need to closely examine what involvement might mean in different cultural and economic contexts. Studying links, for example, between involvement and other constructs in non-Western settings would benefit from first clarifying what involvement might mean in those settings. Finally, one implication for Philippine schools can also be made. Findings point to low-income Filipino parents' conceptualizations of involvement to support their children's schooling and an indication regarding their desire to support their children's success despite the many challenges they face given their circumstances. Administrators and educators can capitalize upon their notions and desires to help their children by helping them develop strategies that fit within parents' beliefs. By starting with these culturally-informed categories of involvement, strategies may be more relevant and meaningful for parents in this specific ecocultural context.

\subsection{Limitations and future research directions}

Findings should be interpreted in light of its limitations. First, careful measures were employed to eliminate potential biases, such as self-presentation among Filipinos (e.g., Lynch, 2013). However, as parenting remains to be a sensitive topic, participants may have been especially prone to social desirability bias. This may especially be the case as during data collection, both the first author and the parents were aware of their differences in educational and socioeconomic background. Although efforts were made to engender equal status between researcher and participants by the choice of methods used here, it is possible that the participants were more inclined to report greater parental involvement knowing that the first author was previously a school teacher. Relatedly, there maybe sampling bias in that parents who agreed to participate in the study were highly involved in their children's academic endeavors to begin with and that parents with low involvement were less likely to volunteer for the study. Future studies should also involve teachers and school administrators to capture different perceptions of parental involvement.

Additionally, this study is limited in that it is uncertain where to attribute the unique, emergent themes such as providing for basic needs and volunteering by cleaning. As parents are simultaneously embedded in multiple contexts, it is plausible that these findings were due to poverty or due to the influences of the Filipino culture, or the 
interaction of both. Further, it is important to note that cur-rent findings may not apply to rural areas in the Philippines which may place different levels of emphasis on parental involvement or academic achievement. Expanding this research to include families from different socioeconomic levels, as well as various geographic locations in the Philippines, could strengthen the findings and help identify factors that most influences parental involvement. Finally, having a balanced sample of female and male caregivers, with male and female children, could increase the transferability of findings.

\section{Authors' contributions}

First author - conceptualization, methodology, formal analysis, investigation, writing - original draft, review and editing

Second author - conceptualization, methodology (design of method), validation, writing - original draft, review and editing

Conflicts of interest - The authors report having no conflicts of interest to declare.

Acknowledgements - The authors wish to acknowledge the support of the Newman Research Travel Fund from the University of Nebraska-Lincoln College of Education and Human Sciences.

\section{References}

Alampay, L. P. (2014). Parenting in the Philippines. Parenting across Cultures: Childrearing, Motherhood and Fatherhood in Non-Western Cultures, 7, 459-474. http://dx.doi.org/10.1007/978-94-007-7503-9

Albert, J. R., Dumagan, J. C., \& Martinez, A. J. (2015). Inequalities in income, labor, and education: The challenge of inclusive growth. In Discussion Paper Series,2015-01. http://ideas.repec.org/p/phd/dpaper/dp 2015-01.html

Albert, J. R., Quimba, F. M., Ramos, A. P., \& Almeda, J. P. (2012). Profile of out-ofschool children in the Philippines. In Discussion Paper Series, 2015-01.

Asian Development Bank. (2004). City development strategies to reduce poverty(June). pp. 1-125.

Baeck, U.-D. K. (2010). Parental involvement practices in formalized home-school cooperation. Scandinavian Journal of Educational Research, 54(6), 549-563. http://dx.doi.org/10.1080/00313831.2010.522845

Bernard, H. R. (2006). Field notes: How to take them, code them, manage them. InH. R. Bernard (Ed.), Research methods in anthropology: Qualitative and quantitative approaches (4th ed., pp. 387-412). Oxford: AltaMira Press. 
Blair, S. L. (2014). Parental involvement and children's educational performance: Acomparison of Filipino and U.S. parents. Journal of Comparative Family Studies,40(3), 351-366.

Bronfenbrenner, U., \& Morris, P. A. (2006). The bioecological model of human development. In R. M. Lerner, \& W. Damon (Eds.), Handbook of child psychology: Theoretical models of human development (pp. 793-828). Hoboken, NJ: John Wiley \& Sons Inc.

Castro, A. D. (2003). Introduction to Giorgi's existential phenomenological research method. Carribean Journal of Psychology, 11, 45-56.

Clarke, C. (2001). The role of parents in Singapore primary schools. Teaching and Learning, 22(2), 83-92.

Clifford, A. P., \& Göncü, A. (2019). Portrayals of parental involvement: Descriptions of family and school relationships in a low-income African American community. Mind, Culture, and Activity, 26(1), 75-92. http://dx.doi.org/10.1080/ 10749039.2019.1587635

Clifford, A. P., \& Humphries, M. L. (2018). Parent involvement in US early childhood education: Benefits, limitations, and reconceptualizations. In M. Fleer, \& B. vanOers (Eds.), International handbook of early childhood education (pp. 767-786).Dordrecht: Springer Netherlands. http://dx.doi. org/10.1007/978-94-024-0927-737

Creswell, J. (2007). Qualitative inquiry and research design: Choosing among five approaches (2nd ed.). Thousand Oaks, CA: Sage Publications.

Creswell, J., \& Miller, D. L. (2000). Determining validity in qualitative inquiry. Theory Into Practice, 39, 124-130. http://dx.doi.org/10.1207/s15430421tip39032

de Guzman, M. R., Carlo, G., \& Edwards, C. P. (2008). Prosocial behaviors in context: Examining the role of children's social companions. International Journal of Behavioral Development, 32(6), 522-530. http://dx.doi. org/10.1177/0165025408095557

de Guzman, M. R. T. (2014). Yaya: Philippine domestic care workers, the children they care for, and the children they leave behind. International Perspectives in Psychology: Research, Practice, Consultation, 3(3), 197-214. http://dx.doi. org/10.1037/ipp0000017

de Guzman, M. R. T., Brown, J., Carlo, G., \& Knight, G. P. (2012). What does it mean to be prosocial? A cross-ethnic study of parental beliefs. Psychology \& Developing Societies, 24(2), 239-268. http://dx.doi.org/10.1177/097133361202 $\underline{400207}$

De la Cruz, M. T., Protacio, E., Balanon, F., Yacat, J., \& Francisco, C. (2001). Trust and power: Child abuse in the eyes of the child and the parent. Manila: Save the Children UK and the United Nations Children's Fund.

Denessen, E., Driessen, G., Smit, F., \& Sleegers, P. (2001). Culture differences in education: Implications for parental involvement and educational policies. $a$ Bridge to the Future, 55-65. http://www.ernape.net/articles/2001/session1/ DENESS 1.PDF 
Eccles, J. S., \& Harold, R. D. (1993). Parent-school involvement during the early adolescent years. Teachers College Record, 94(3), 568-587.

Edwards, C. P., \& Bloch, M. (2010). The Whiting's' concepts of culture and how they have fared in contemporary psychology and anthropology. Journal of Cross-Cultural Psychology, 41(4), 485-498. http://dx.doi. org/10.1177/0022022110362566

Edwards, C. P., \& Kutaka, T. S. (2015). Diverse perspectives of parents, diverse concepts of parent involvement and participation: What can they suggest to researchers? Research on Family-School Partnerships, 35-53. http://dx.doi. org/10.1007/978-3-319-13838-13

El Nokali, N. E., El Bachman, H. J., \& Votruba-Drzal, E. (2011). Parent involvement and children's academic and social development in elementary school. Child Development, 81(3), 988-1005. http://dx.doi. org/10.1111/j.1467-8624.2010.01447.x.Parent

Enriquez, V. (1994). From colonial to liberation psychology. Manila: De La Salle University Press.

Epstein, J. L. (1995). School/family/community partnerships: Caring for the children we share. Phi Delta Kappan, 701-712.

Fan, X., \& Chen, M. (2001). Parental involvement and students' academic achievement: A meta-analysis. Educational Psychology Review, 13(1), 1-22. http://dx.doi.org/10.1023/A:1009048817385

Fantuzzo, J., Tighe, E., \& Childs, S. (2000). Family Involvement Questionnaire: A multivariate assessment of family participation in early childhood education. Journal of Educational Psychology, 92(2), 367-376. http://dx.doi. org/10.1037/0022-0663.92.2.367

Fleharty, H., \& Edwards, C. (2013). Family-school partnerships: Promoting family participation in K-3 teacher professional development. Mathematics Teacher Educator, 2(1), 55-73.

García Coll, C. T., Akiba, D., Palacios, N., Bailey, B., Silver, R., DiMartino, L., \& Chin, C.(2002). Parental involvement in children's education: Lessons from three immigrant groups. Parenting: Science and Practice, http://dx.doi.org/10.1207/ S15327922PAR0203 05

Georgiou, S. N. (1996). Parental involvement: Definition and outcomes. Social Psychology of Education, 1(3), 189-209. http://dx.doi.org/10.1007/BF02339890

Göncü, A., Tuermer, U., Jain, J., \& Johnson, D. (1999). Children's play as cultural activity. In A. Göncü (Ed.), Children's engagement in the world (pp. 148-172). Cambridge, MA: Cambridge University Press.

Grolnick, W. S., Kurowski, C. O., \& Gurland, S. T. (1999). Family processes and the development of children's self-regulation. Educational Psychologist, 34(1), 3. http://dx.doi.org/10.1207/s15326985ep3401 1

Hallinger, P., \& Kantamara, P. (2001). Exploring the cultural context of school improvement in Thailand. School Effectiveness and School Improvement, 12(4),385-408. http://dx.doi.org/10.1076/sesi.12.4.385.3446 
Hango, D. (2007). Parental investment in childhood and educational qualifications: Can greater parental involvement mediate the effects of socioeconomic disadvantage? Social Science Research, 36(4), 1371-1390. http://dx.doi. org/10.1016/j.ssresearch.2007.01.005

Harkness, S., \& Super, C. M. (2006). Themes and variations: Parental ethnophobia's in Western cultures. In K. H. Rubin, \& O. B. Chung (Eds.), Parental beliefs, parenting, and child development in cross-cultural perspective (pp. 61-79). New York, NY: Psychology Press.

Hill, N. E., Castellino, D. R., Lansford, J. E., Nowlin, P., Dodge, K. A., Bates, J. E., \&Pettit, G. S. (2004). Parent academic involvement as related to school behavior, achievement, and aspirations: Demographic variations across adolescence. Child Development, 75(5), 1491-1509. http://dx.doi. org/10.1111/j.1467-8624.2004.00753.x

Hornby, G., \& Lafaele, R. (2011). Barriers to parental involvement in education: an explanatory model. Educational Review, 63(1), 37-52. http://dx.doi.org/10.1080 $\angle 00131911.2010 .488049$

Keller, H. (2013). Attachment and culture. Journal of Cross-Cultural Psychology,44(2), 175-194. http://dx.doi.org/10.1177/0022022112472253

Lansford, J. E., Alampay, L. P., Al-Hassan, S., Bacchini, D., Bombi, A. S., Bornstein, M.H., ... , \& Zelli, A. (2010). Corporal punishment of children in nine countries as a function of child gender and parent gender. International Journal of Pediatrics,1-12. http://dx.doi.org/10.1155/2010/672780

Lareau, A. (1987). Social class differences in family-school relationships: The importance of cultural capital. Sociology of Education, 60(2), 73-85.

Maligalig, D., Caoili-Rodriguez, R., Martinez, A., \& Cuevas, S. (2010). Education outcomes in the Philippines. Manila, Philippines: Asian Development Bank.

Malone, D. (2014). Culture: A potential challenge for parental involvement in schools. 14-19. The Delta Kappa Gamma: International Journal for Professional Educators.

Marcon, R. A. (1999). Positive relationships between parent school involvement and public school inner-city preschoolers' development and academic performance. School Psychology Review, 28(3), 395-412.

McWayne, C. M., Melzi, G., Schick, A. R., Kennedy, J. L., \& Mundt, K. (2013). Defining family engagement among Latino Head Start parents: A mixedmethods measurement development study. Early Childhood Research Quarterly, 28(3),593-607. http://dx.doi.org/10.1016/j.ecresq.2013.03.008

Miech, R., Essex, M. J., \& Hill Goldsmith, H. (2001). Socioeconomic status and the adjustment to school: The role of self-regulation during early childhood. Sociology of Education, 74(2), 102-120. http://dx.doi.org/10.2307/2673165

Pe-Pua, R. (2006). From decolonizing psychology to the development of acrossindigenous perspective in methodology: The Philippine experience. In U.Kim, K.-S. Yang, \& K.-K. Hwang (Eds.), Indigenous and cultural psychology: Understanding people in context (pp. 109-137). New York, NY: Springer Science + Business Media. http://dx.doi.org/10.1007/0-38728662-4 5 
Pe-Pua, R., \& Protacio-Marcelino, E. A. (2000). Sikolohiyang Pilipino (Filipino psychology): A legacy of Virgilio G. Enriquez. Asian Journal of Social Psychology,3(August), 49-71. http://dx.doi.org/10.1111/1467-839X.00054

Philippine Institute for Development Studies. (2012). Education for all: Addressing problems in primary schooling. Development Research News, 30(6), 1-8.

Philippine Statistics Authority. (2015). Out-of-school children and youth in the Philippines (Results from the 2013 Functional Literacy, Education and Mass MediaSurvey).. https://psa.gov.ph/content/out-school-children-and-youthphilippines-results-2013-functional-literacy-education-and 28.09.18

Pomerantz, E. M., Moorman, E., \& Litwack, a. S. D. (2007). The how, whom, and why of parents' involvement in children's academic lives: More is not always better. Review of Educational Research, 77(3), 373-410. http://dx.doi. org/10.3102/003465430305567

Reyes, M. L., \& Galang, A. J. R. (2009). Motivational and social aspects of the Filipino college experience. Philippine Journal of Psychology, 42(2), 213-235.

Reyes, M. L., \& Resurrection, K. F. (2015). The self in family coexistence: developing youth's agency and PR sociality. Contemporary Social Science, 10(1), 52-69. http://dx.doi.org/10.1080/21582041.2014.980841

Seginer, R. (2006). Parents' educational involvement: A developmental ecology perspective. Parenting: Science and Practice, 6(1), 1-48. http://dx.doi. org/10.1207/s15327922par0601 1

Super, C. M., \& Harkness, S. (1986). The developmental niche: A conceptualization at the interface of child and culture. International Journal of Behavioral Development, http://dx.doi.org/10.1177/016502548600900409

Sy, S. R. (2006). Rethinking parent involvement during the transition to first grade: A focus on Asian American families. The School Community Journal, 16(1), 107-126.

Tabbada-Rungduin, T., Abulon, E. L., Fetalvero, L., \& Suatengco, R. (2014). Exploring parental involvement and teachers' activities in early literacy development. International Journal of Research Studies in Education, 3(3), 3-19.

Trumbull, E., Rohstein-Fisch, C., \& Hernandez, E. (2003). Parent involvement in schooling-According to whose values? The School Community Journal, 13(2),45-72.

Turney, K., \& Kao, G. (2009). Barriers to school involvement: Are immigrant parents disadvantaged? The Journal of Educational Research, 102(4), 257-271. http:// dx.doi.org/10.3200/JOER.102.4.257-271

Usher, A., Kober, N., Jennings, J., \& Rentner, D. S. (2012). What roles do parent involvement, family background, and culture play in student motivation? The George Washington University, (2009), 1-14.

Wainryb, C. (2006). Moral development in culture: Diversity, tolerance, and justice. In M. Killen, \& J. G. Smetana (Eds.), Handbook of moral development (pp.211240). Mahwah, NJ: Lawrence Erlbaum Associates.

Wang, M. T., \& Sheikh-Khalil, S. (2014). Does parental involvement matter for student achievement and mental health in high school? Child Development,85(2), 610-625. http://dx.doi.org/10.1111/cdev.12153 
Weisner, T. S. (1997). The ecocultural project of human development: Why ethnography and its findings matter. Ethos, 25(2), 177-190. http://dx.doi. org/10.1525/eth.1997.25.2.177

Weisner, T. S. (2002). Ecocultural understanding of children's development pathways. Human Development, 45, 275-281. http://dx.doi. org/10.1159/000064989

Whiting, J. W. M. (1994). A model for psychocultural research. In E. H. Chasdi (Ed.),Culture and human development: The selected papers of John Whiting (pp.89-104). New York: Cambridge University Press.

Yap, R. H. D. (2011). K to 12: The key to quality education?. https://www.senate.gov. ph/publications/PB 2011-02-Kto12TheKeytoQuality.pdf

Ying, Y. W., \& Han, M. (2008). Parental acculturation, parental involvement, intergenerational relationship and adolescent outcomes in immigrant Filipino American families. Journal of Immigrant \& Refugee Studies, 6(1), 112-131. http://dx.doi.org/10.1080/15362940802119351

Yoder, J. R., \& Lopez, A. (2013). Parent's perceptions of involvement in children's education: Findings from a qualitative study of public housing residents. Child and Adolescent Social Work Journal, 30(5), 415-433. http://dx.doi.org/10.1007/ s10560-013-0298-0

Zellman, G. L., Perlman, M., \& Karam, R. (2014). How Moroccan mothers and fathers view child development and their role in their children's education. International Journal of Early Years Education, 22(2), 197-209. http://dx.doi.org/ $\underline{10.1080 / 09669760.2014 .909307}$ 